\title{
CHARACTERIZATION OF BOTSWANA COAL FROM TWO COAL FIELDS: MABESEKWA AND MMAMABULA TO DETERMINE ITS COAL RANK
}

\author{
MMOLOKI MAKOBA ${ }^{a *}$, TABOKA MOALOSI ${ }^{a}$, PAUL S. AGACHI ${ }^{a, b}$, \\ EDISON MUZENDA ${ }^{a}$, TIRIVAVIRI A. MAMVURA ${ }^{a}$
}

\begin{abstract}
Coal samples from two different coal fields: Mabesekwa and Mmamabula were collected (with six seams from each coal field) to characterize using X-Ray diffractometer (XRD), Scanning Electron Microscopy (SEM) and Fourier Transform Infrared (FT-IR) spectroscopy. Proximate and ultimate analysis are also given. Clay minerals kaolinite, pyrite, dolomite, siderite and calcite, and quartz were discovered. Comparing measurements of C, VM, GCV, $\mathrm{MC}$ and $\mathrm{FC}$ obtained from the samples with literature, Botswana coal identifies as lignite grade $A$ coal suitable for applications in coal gasification and ammonia based fertilisers due to its high volatile matter and high reactivity of char. The paper looks to use different methods to analyse Botswana coal and recommend its potential applications based on literature.
\end{abstract}

Keywords: Botswana coal, characterization, XRD, SEM, FT-IR, coal rank

\section{INTRODUCTION}

Botswana coal is not extensively studied despite the country's huge coal resources of around 212 Billion tons[1]. There are currently 8 coal fields across the country lying on the eastern side. Coal samples for this paper have been collected from two different mining points; Mabesekwa and Minergy (see Figure 1) to study how coal varies across the Karoo supergroup which is a belt that runs in the southern part of the African continent [2] covering $2 / 3^{\text {rd }}$ of Botswana's geological strata.

\footnotetext{
a Department of Chemical, Materials and Metallurgical Engineering, Faculty of Engineering and Technology, Botswana International University of Science and Technology, Palapye, Botswana

b Department of Chemical Engineering, Faculty of Chemistry and Chemical Engineering, University Babes-Bolyai, Cluj-Napoca, Romania

* Corresponding author: mmoloki.makoba@studentmail.biust.ac.bw
} 
This study of coal composition and rank was influenced by research on gasification of Botswana coal for synthetic gas production. Coal is considered complex and heterogeneous in nature, therefore in order to understand coal before any process it is important to know its structure specific to its location. In an attempt to understand coal, different analyses can be carried out.

Mabesekwa coal field is located in the north eastern part of Botswana currently being explored by Shumba coal while Mmamabula coal field is located in the south eastern part of Botswana (Figure 1) with Minergy coal currently mining there for export to South Africa. These two constitute one of the key coal fields in the Botswana and can be well representative of the country's deposit (North and South). It is important to study all coal seams as mining of coal can change from shallow to deep.

X-ray diffraction (XRD) presents an average of the coal sample intensities rather than local properties of coal [4] which represents coal well because it is heterogeneous in nature. XRD is a non-destructive method that has been established to determine crystalline materials contained in coal.

FT-IR spectroscopy is also a non-destructive analytical tool which allows for study of functional groups. It identifies molecular vibrations in stretching and bending groups extensively identifying chemical structure of coal. The morphological structure was determined using the scanning electron microscopy (SEM). These analytical tools have been coupled with thermogravimetric analyzer (TGA) to give thermodynamic properties of coal.

In this work, we report information on structural parameters of Botswana coal determined by X-Ray diffraction, FT-IR spectroscopy and Scanning electron microscopy. Volatile matter, gross calorific value and fixed carbon are used to establish coal ranks. Volatile matter increases with decrease in rank [1].

\section{RESULTS AND DISCUSSION}

\subsection{Proximate \& ultimate analysis}

Characterization of Botswana coal is reported in a table form as proximate analysis, ultimate analysis and gross calorific value of six (6) coal seams from Mabesekwa coal mine in the north eastern part of Botswana. The coal was floated in a fluid of specific gravity 1.80 using dense medium separator (DMS). 
CHARACTERIZATION OF BOTSWANA COAL FROM TWO COAL FIELDS: MABESEKWA AND MMAMABULA TO DETERMINE ITS COAL RANK

Table 1. Proximate and ultimate analysis of Mabesekwa coal

\begin{tabular}{|c|c|c|c|c|c|c|c|c|}
\hline \multicolumn{3}{|c|}{ Sample Identification } & \multicolumn{6}{|c|}{ SHUMBA COAL } \\
\hline & & & A & B & C & D & E & $\mathbf{F}$ \\
\hline \multirow{7}{*}{ 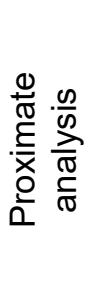 } & Yield & mass $(\mathrm{g})$ & 143 & 1362 & 1090 & 381 & 50 & 167 \\
\hline & & $\%$ & 0.4 & 4.4 & 2.9 & 1.0 & 0.1 & 0.6 \\
\hline & $A C$ & $\%$ & 33.4 & 39.8 & 45.0 & 37.2 & 35.2 & 35.9 \\
\hline & MC & $\%$ & 3.1 & 4.6 & 4.2 & 4.2 & 5.4 & 5.2 \\
\hline & VM & $\%$ & 24.4 & 22.9 & 20.7 & 24.0 & 23.6 & 24.8 \\
\hline & FC & $\%$ & 39.1 & 32.7 & 30.2 & 34.6 & 35.9 & 34.2 \\
\hline & GCV & $(\mathrm{MJ} / \mathrm{kg})$ & 15.3 & 12.7 & 12.1 & 14.0 & 14.2 & 13.6 \\
\hline \multirow{4}{*}{ 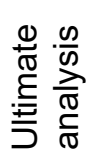 } & C & $\%$ & 41.2 & 35.4 & 33.2 & 38.2 & 38.3 & 37.0 \\
\hline & $\mathrm{H}$ & $\%$ & 2.01 & 2.07 & 2.20 & 2.20 & 1.97 & 2.01 \\
\hline & $\mathrm{N}$ & $\%$ & 0.87 & 0.81 & 0.78 & 0.82 & 0.83 & 0.85 \\
\hline & $\mathrm{O}$ & $\%$ & 18.1 & 17.2 & 14.6 & 17.2 & 18.3 & 19.0 \\
\hline
\end{tabular}

Proximate analysis reports the physical characteristics of coal being moisture content, ash content, volatile matter, fixed carbon and total Sulphur contained. Fixed carbon is obtained by difference in percentage.

Seam A contains the least ash and subsequently the most fixed carbon. Coal is amorphous in nature; it depends on what was dumped and buried at the time when that layer/ seam was formed. Seam A seems to be purer with the highest amount of volatile matter and hence highest calorific value. High moisture content is generally believed to reduce the value of coal as indicated in Table 1. This will in turn lead to a large decrease of product gas efficiency due to the increase of the equivalence ratio in an attempt to keep the exit temperature of the gasifier at the specified value [5].

Table 1 also reports ultimate analysis of the elements i.e. $\mathrm{C}, \mathrm{H}, \mathrm{N}$ and $\mathrm{O}$ contained in six seams from Mabesekwa coal field. These elements form a typical structure of coal but it is how they are bonded together that makes coal unique and of certain value. The bonds in coal are identified through FTIR spectroscopy as explained in section 3.2. According to analysis of coal ranks by [6]-[8] Botswana coal identifies as lignite grade $A$ coal with $\mathrm{C}$ content of $40 \%, \mathrm{VM}-24 \%, \mathrm{GCV}-13.6 \mathrm{MJ} / \mathrm{kg}$ and $\mathrm{MC}-4 \%$. Lignite type coal proves to be more efficient as a coal gasification feedstock [9] because of its high volatile matter content and high reactivity of char therefore Botswana coal will fit best for application for gasification process.

With these elements together with functional groups analysis, a chemical formula for Botswana coal can be predicted. According to [1], all coals have nearly identical infrared spectra but differ in relative intensity of component bands which are broad and poorly defined due to a wide range of coal structures. 
Mmamabula West coal had 6 seams and the proximate analysis results are represented in Table 3 . This coal has at most $10 \%$ moisture compared with Mabesekwa coal with only 5\% moisture. TGA analyses inherent moisture. Moisture reduces heating value of coal [10] therefore low inherent moisture coal is promising for a better-quality coal. Seam A for both Mabesekwa and Mmamabula coals show the least amount of moisture. This can be explained by the hot weather in Botswana that evaporates off water from the top surfaces compared to water that tends to settle at the bottom of the rock bed.

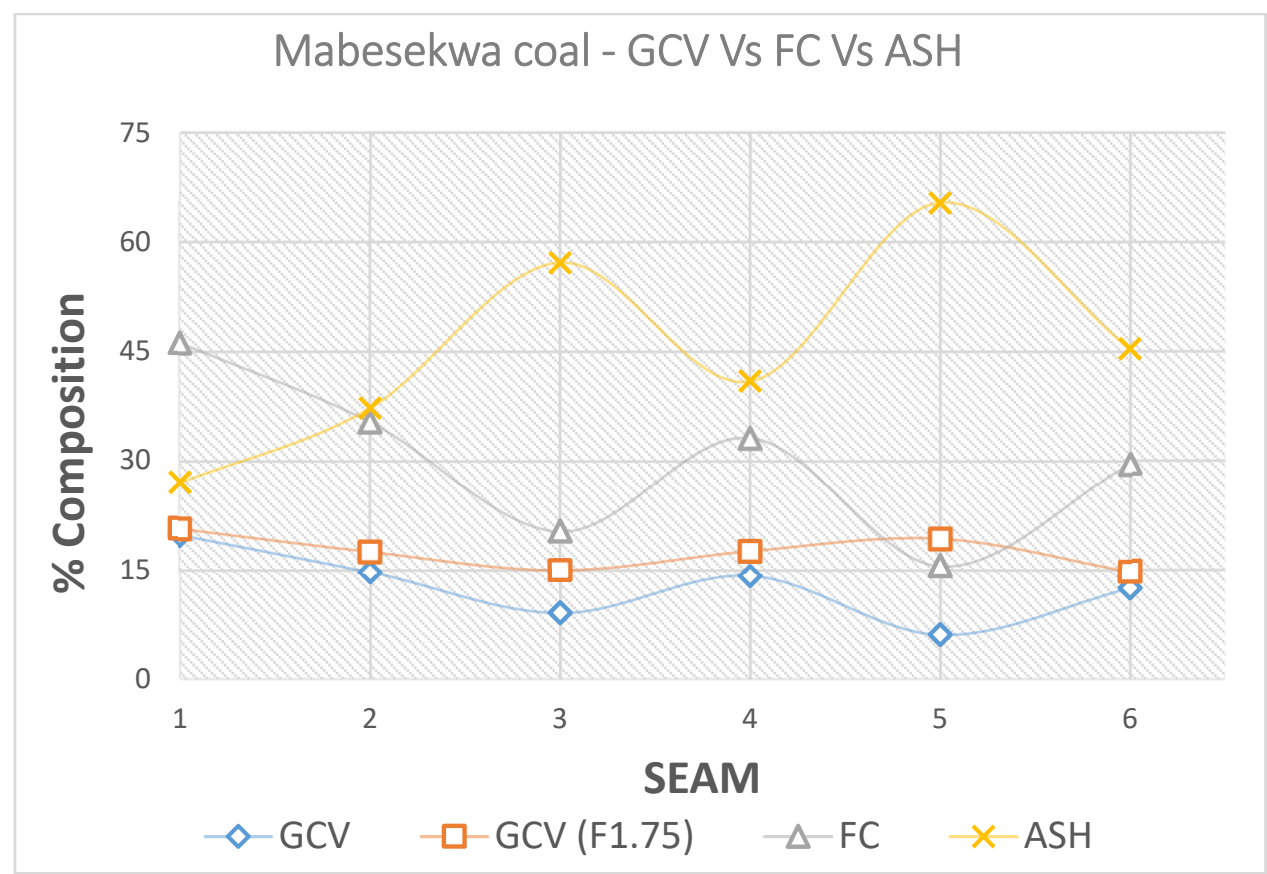

Figure 1. Proximate analysis variations across coal seams.

Fixed carbon for coal that was floated in low density medium (1.75) before testing is higher than raw coal because what weighs the most is usually invaluable inorganic material that sunk. 
Table 2. Proximate and ultimate analysis of Minergy coal

\begin{tabular}{|c|c|c|c|c|c|c|c|c|}
\hline \multicolumn{3}{|c|}{ Sample Identification } & \multicolumn{6}{|c|}{ MINERGY COAL } \\
\hline & & & A & B & C & D & $E$ & $\mathbf{F}$ \\
\hline \multirow{5}{*}{ 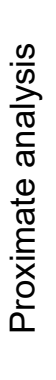 } & Yield & & & & & & & \\
\hline & $A C$ & $\%$ & 63.9 & 25.2 & 17.7 & 18.3 & 21.2 & 29.9 \\
\hline & $\mathrm{MC}$ & $\%$ & 3.2 & 7.2 & 7.3 & 6.5 & 5.4 & 4.7 \\
\hline & VM & $\%$ & 15.4 & 26.2 & 21.8 & 26.9 & 26.0 & 25.0 \\
\hline & FC & $\%$ & 17.5 & 41.4 & 53.2 & 48.3 & 47.4 & 40.4 \\
\hline \multirow{4}{*}{ 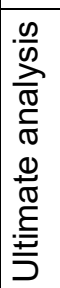 } & $C$ & $\%$ & 20.9 & 51.3 & 58.1 & 58.5 & 55.9 & 49.8 \\
\hline & $\mathrm{H}$ & $\%$ & 2.01 & 3.52 & 3.82 & 4.07 & 3.66 & 3.68 \\
\hline & $\mathrm{N}$ & $\%$ & 0.37 & 1.05 & 1.30 & 1.20 & 1.12 & 1.03 \\
\hline & $S$ & $\%$ & 0.19 & 2.47 & 2.57 & 1.60 & 3.21 & 1.90 \\
\hline
\end{tabular}

$\%$ FC shows to decrease with increase in density medium as expected. This increase is proportional to ash content, the more the ash content the more increase in fixed carbon after dense medium separation. this is because ash composes of predominantly inorganic matter which does not add value to coal. Looking at the GCV for each seam.

From graph, $\mathrm{FC}$ and $\mathrm{AC}$ follow a similar pattern showing to complement each that proving that coal is indeed made up of organic matter that burns out completely leaving inorganic matter that is ash. GCV and AC are indirectly proportional, the higher the heating value, the lower the ash content and vice versa. Seam E shows to have $65 \%$ ash content; coal was made from dead plants and animals that were buried thousands of years ago. Coal which was floated at density 1.75 of liquid medium has more value than raw coal, this is explained by higher gross calorific value. 
MMOLOKI MAKOBA, TABOKA MOALOSI, PAUL S. AGACHI, EDISON MUZENDA, TIRIVAVIRI A. MAMVURA

\subsection{FT-IR}

Combining elemental analysis with functional groups analysis enables a chemical formula for that particular coal can be predicted. Functional groups present show to be aromatic $\mathrm{C}=\mathrm{C}$ bending groups at wavenumber 1700 $1500, \mathrm{C}=\mathrm{C}$ bending alkene and $\mathrm{CH}_{2}$ bend at $730-665$ and $1480-1440$ respectively. According to [1], all coals have nearly identical infrared spectra but differ in relative intensity of component bands which are broad and poorly defined due to a wide range of coal structures.

The coal samples showed intense peaks between $400 \mathrm{~cm}^{-1}$ and 1100 $\mathrm{cm}^{-1}$. According to [11] these peaks indicate clay minerals (kaolinite, pyrite, siderite, dolomite) and quartz. These results can be correlated with XRD results as they also showed intense peaks of these clay minerals. From the graph it can be noticed that seam $A$ had the highest intensities of the clay minerals. The peaks around $1600 \mathrm{~cm}^{-1}$ indicate $\mathrm{C}=\mathrm{C}$ bonds.

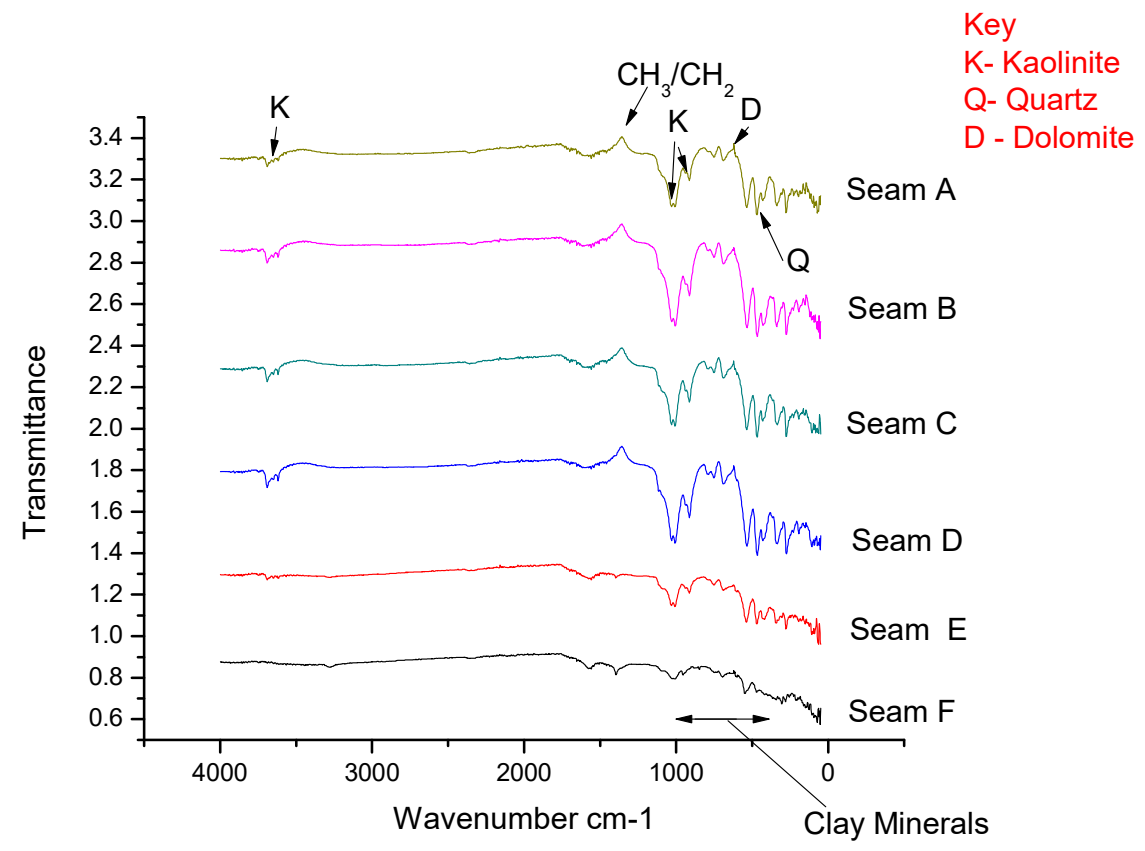

Figure 2. FT-IR spectra for six Mabesekwa coal samples. 


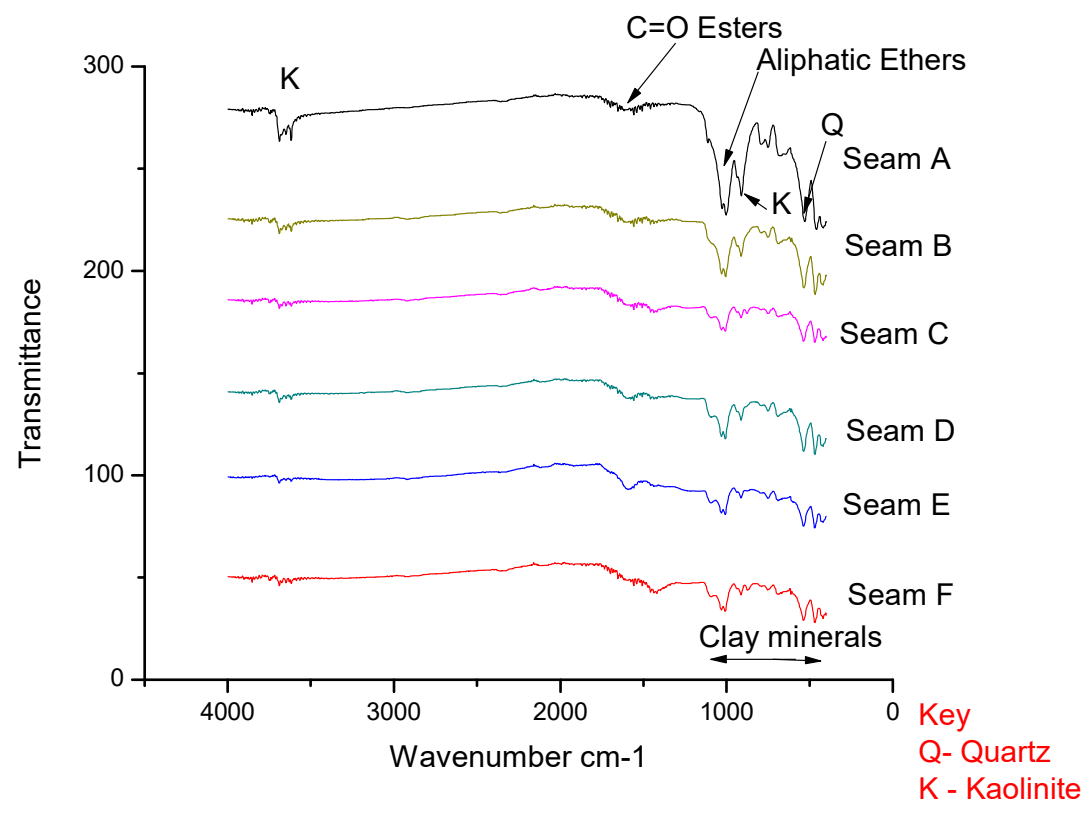

Figure 3. FT-IR spectra for 6 Mmamabula coal samples.

\section{$1.3 \quad X$-Ray diffraction}

$\mathrm{XRD}$ analysis showed the presence of minerals in their varying intensities in the coal samples. These minerals included analcime, quartz, kaolinite, dolomite, calcite, pyrite and siderite. Minerals identified by FTIR analysis are also detected by XRD. Its only about $2 \%$ of unidentified peak area which are minerals that are unclassified. [3] states that coal is made up of mineral and organic matter. The mineral matter contained in coal influences the type of ash and gaseous components to be produced when coal burns. For example, pyrite $\left(\mathrm{FeS}_{2}\right)$, which was one of the minerals found in the coal, would produce iron oxide (ash) and $\mathrm{SiO}_{2}$ (gas). 
MMOLOKI MAKOBA, TABOKA MOALOSI, PAUL S. AGACHI, EDISON MUZENDA, TIRIVAVIRI A. MAMVURA

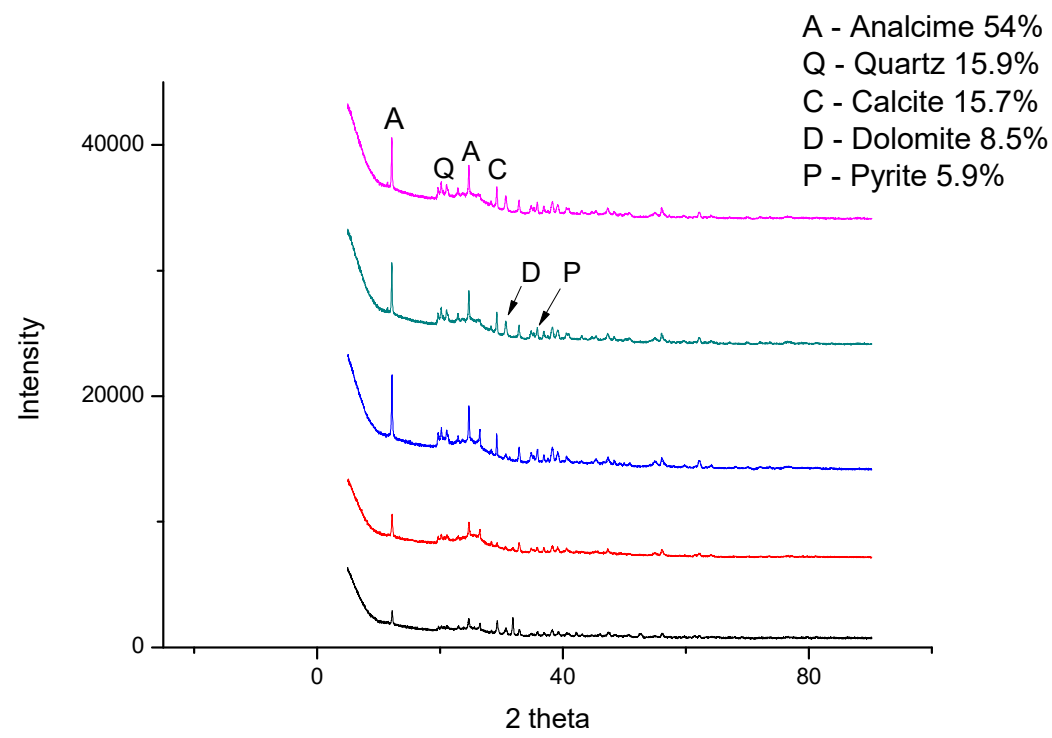

Figure 4. XRD analysis for Mabesekwa coal samples seams A - F from top to bottom.

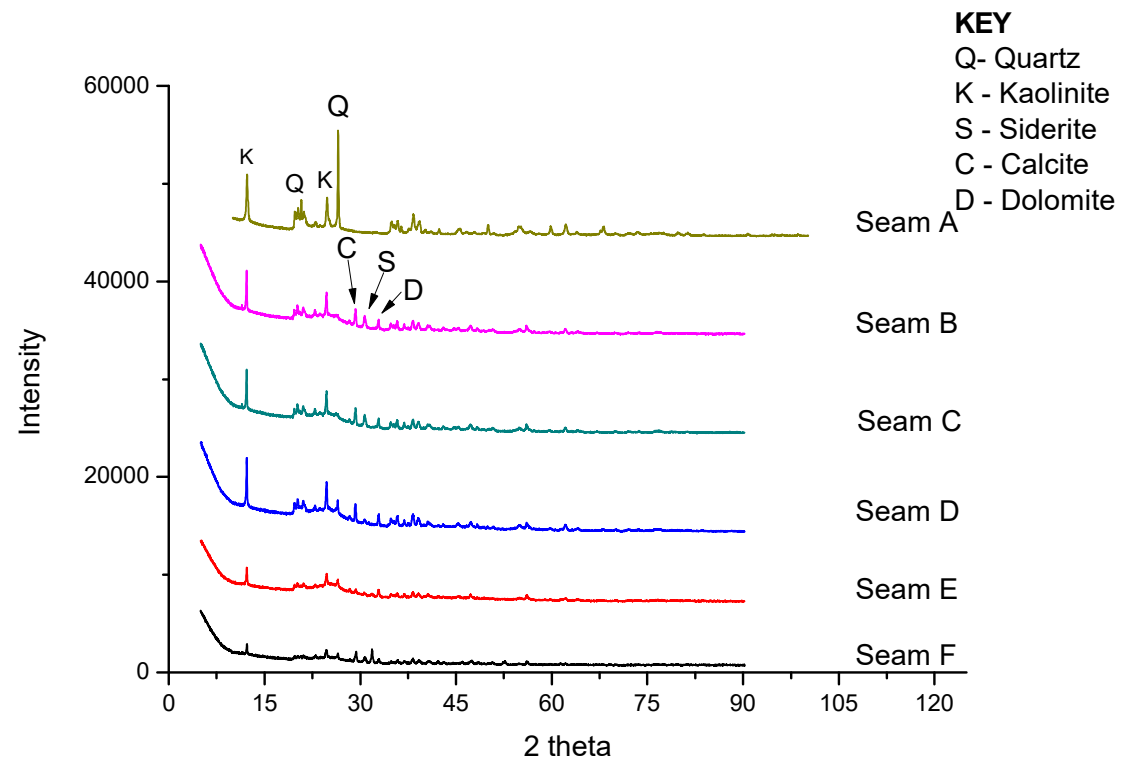

Figure 5. XRD analysis showing an estimate of crystallinity in Mmamabula coal samples, seams $A-F$ from top to bottom. 
That is why it is important to understand and quantify the mineral matter contained in coal. Mineral matter is thought of as a geochemical indicator.

$X R D$ analyses crystalline materials which are materials with long range of order, amorphous content in samples cannot be identified but can be calculated from the data collected.

It is necessary to assess the beneficial and detrimental effects that the mineral matter (before and after processing) may have both on the process in which it is involved and on its ultimate disposal.

Ash indicates the incombustible inorganic material that remains after coal burns. It can include clay minerals such as carbonates and Sulphur compounds, and quartz. It is also viewed as an unwanted coal property that degrades coal value [2]. Sulphur content is at an average 1.99\% in Botswana coal.

\subsection{SEM}

Figure 5 shows the SEM images of the 6 Minergy coal samples. SEM describes surface morphology by visual magnification of the surface. This SEM is equipped with energy dispersive $x$-ray spectrometers (EDX) that allow qualitative and quantitative chemical analysis. SEM images can provide valuable information such as particle size, swelling of the particles during conversion, and the structure of char/ash. The images are used to estimate particle size and porosity in samples.
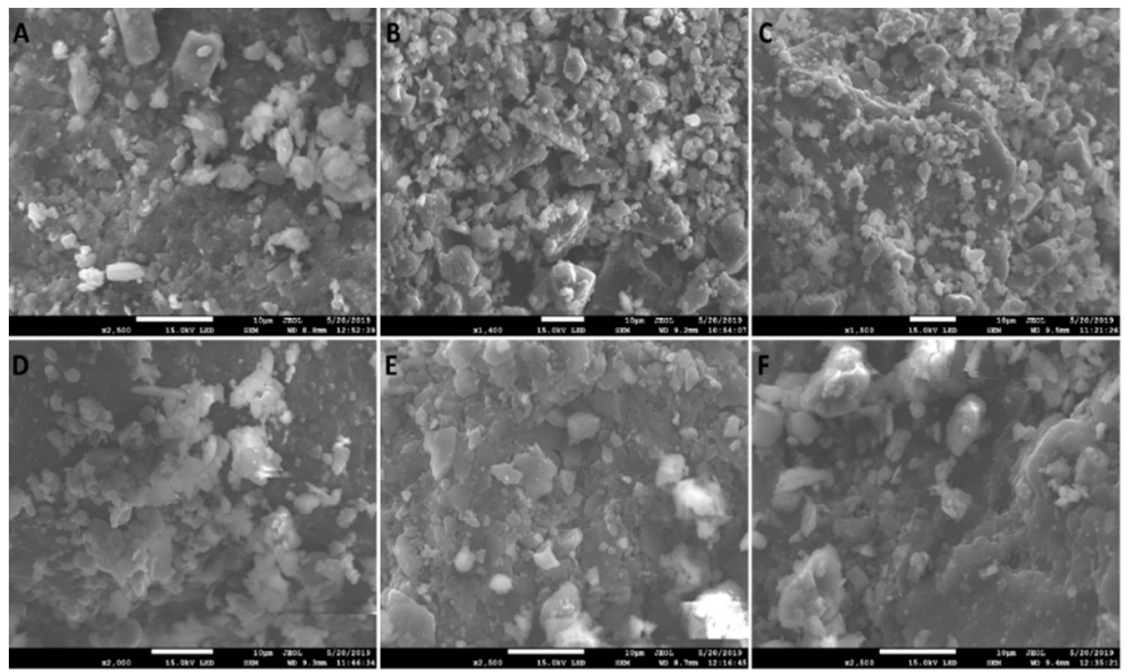

Figure 6. 2-D SEM images for porosity comparison of 6 Minergy coal samples. 
SEM details topography, crystallography and composition of the material being investigated. A good knowledge of the morphology of coal is necessary in proposing suitable ways of cleaning coal.

Energy Dispersive X-ray (EDX) analysis produced elemental analysis of the seams. Table 4 shows the EDS results of Seam $C$ at $12 \mathrm{~m}$ to $13 \mathrm{~m}$. these results show dominant carbon in the sample followed by oxygen. These are other trace elements in the sample. Hydrogen is not present in the EDX spectrum because EDX is related to the K-shells which are not the valence shell[12]. $\mathrm{H}$ has only a $\mathrm{K}$ shell in covalent bonding and this is the only shared electron.

Table 3. EDS results of Seam A showing the elements contained

\begin{tabular}{c|c|c|c|}
\hline $\begin{array}{c}\text { Element } \\
\text { Line }\end{array}$ & Weight \% & Atom \% & Formula \\
\hline $\boldsymbol{C} \boldsymbol{K}$ & 65.72 & 73.78 & $\mathrm{C}$ \\
\hline $\boldsymbol{O} \boldsymbol{K}$ & 27.50 & 23.18 & $\mathrm{O}$ \\
\hline $\boldsymbol{M g} \boldsymbol{K}$ & 0.10 & 0.06 & $\mathrm{Mg}$ \\
\hline $\boldsymbol{A l} \boldsymbol{K}$ & 2.38 & 1.19 & $\mathrm{Al}$ \\
\hline $\boldsymbol{S i} \boldsymbol{K}$ & 2.46 & 1.18 & $\mathrm{Si}$ \\
\hline $\boldsymbol{S} \boldsymbol{K}$ & 0.53 & 0.22 & $\mathrm{~S}$ \\
\hline $\boldsymbol{K} \boldsymbol{K}$ & 0.03 & 0.01 & $\mathrm{~K}$ \\
\hline $\boldsymbol{C a} \boldsymbol{K}$ & 0.77 & 0.26 & $\mathrm{Ca}$ \\
\hline $\boldsymbol{F e} \boldsymbol{K}$ & 0.52 & 0.12 & $\mathrm{Fe}$ \\
\hline
\end{tabular}

EDX is not reliable in characterizing the whole coal as it only analysis a certain point which cannot be taken as a representation of the whole coal sample. It shows that coal has trace elements including Titanium, Iron, Calcium and Potassium varying through the coals. EDX is used to observe compositional analysis of coal, elements contained are determined by $\mathrm{x}$-ray peak intensity.

\section{CONCLUSIONS}

Botswana coal is Lignite grade A. Clay minerals; kaolinite, dolomite, siderite and calcite, and quartz were discovered. The depth of coal has no relevance in the degree of coalification. Preconcentrating coal with density of 1.75 enriched it to $37 \%$ more purity. 
According to Lignite Energy Council in the US, $13.5 \%$ of lignite is used in the production of synthetic natural gas while $7.5 \%$ is used in ammoniabased fertilizers. Low rank coals are preferable for application in gasification process as they produce better syngas yield compared to caking high rank bituminous coals.

Characterization is an initial stage in the plan to carry out gasification of Botswana coal. These results will enable the prediction in the design of a gasifier being able to predict the yield from the process and ash content.

Seams $B$ to $F$ are highly recommended for gasification process with higher contents of fixed carbon and Hydrogen which will yield high quality synthetic gas.

\section{EXPERIMENTAL}

\section{Sample Selection}

Coal is heterogenous in nature and given this complexity is it necessary to select a representative sample of the main sample.

To ensure a representative sample is collected, correct sampling procedures were followed and certain rules adhered to. The main sample was thoroughly mixed; seams are layers of these composites; they vary depending on how much was buried at that time.

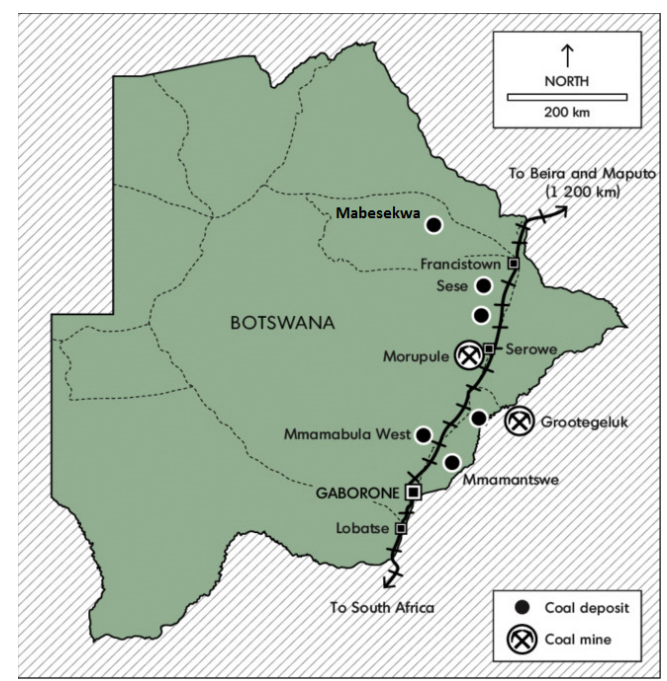

Figure 7. Botswana coal fields map indicating two coal fields for this study: Mabesekwa (North) and Mmamabula west (South) [3] 
MMOLOKI MAKOBA, TABOKA MOALOSI, PAUL S. AGACHI, EDISON MUZENDA, TIRIVAVIRI A. MAMVURA

\section{Sample preparation}

Samples were collected from two different coal fields (Mabesekwa \& Mmamabula, shown in Figure 1) with each having a set of six samples termed as coal seams A to $F$. A total of 12 samples were further sampled to get a representative sample enough to be ground to $45-100 \mu \mathrm{m}$ size fractions in a ball mill pulverisette after drying in an oven. Either than grinding, the pulverisette allowed for proper mixing and homogenizing of coal sample. The top most seam was at least $10 \mathrm{~m}$ below the ground for both coal fields.

\section{Coal characterization}

\section{Proximate and ultimate analysis}

A thermogravimetric analyzer Lego TGA701 was used for proximate analysis to determine moisture, ash, volatile matter, and fixed carbon contents of Botswana coal. About $1 \mathrm{~g}$ of each sample was loaded into a crucible in a thermogravimetric analyzer. The six coals were then subjected to devolatilization and combustion at temperature of $105{ }^{\circ} \mathrm{C}$, for moisture content analysis temperature rose to $950{ }^{\circ} \mathrm{C}$ for volatiles and $750{ }^{\circ} \mathrm{C}$ for ash. Fixed carbon was calculated using differences in percentages.

Ultimate analysis was performed under standard laboratory conditions with Bureau Veritas South Africa.

\section{XRD Analysis}

The pulverized coal was further crushed using a laboratory porcelain mortar to further increase the surface area. A smaller holder was filled up with the sample ensuring a smooth surface which was put into the XRD for analysis. XRD data were obtained from a Bruker D8 Advance powder diffractometer with a $3.0 \mathrm{~kW}$ generator, a Copper $(\mathrm{Cu})$ tube X-ray source, and a LynxEye XE energy-dispersive strip detector. The radiation used is a Copper $\mathrm{K}$ alpha with a wavelength of 1.54056 . The machine was run at $40 \mathrm{~V}$ and $40 \mathrm{~mA}$ for 20 minutes for one sample. The sample data was collected from the angles 10 to 70 an increase of 0.029 degrees per step for a total time of about 20 minutes.

\section{FT-IR measurements}

An FT-IR spectrometer of model Vertex $70 x$ was used. The sample was placed on the sample stand on the equipment. The process ran with infrared light incident to coal sample such that some light was absorbed and some reflected. The information collected was interpreted by the computer which produced data. The range of wavelength specifically for coal was specified. The process was repeated three times for the 12 different samples. 


\section{SEM analysis}

A JSM-7100F scanning electron microscope was used. The pulverized samples were placed on 6 different specimen mounts with carbon coating before being placed in the sample holder.

\section{Nomenclature}

$\begin{array}{ll}\text { VM } & \text { volatile matter } \\ \text { GCV } & \text { gross calorific value } \\ \text { MC } & \text { moisture content } \\ \text { FC } & \text { fixed carbon } \\ \text { TGA } & \text { thermogravimetric analyzer }\end{array}$

\section{ACKNOWLEDGEMENTS}

The authors would like to thank BIUST technicians who worked tirelessly to help us generate results for this publication. We would also like to thank Botswana International University of Science of Technology (BIUST) and Pyro Carbon Energy for the financial support through initiation grant number 041.

\section{REFERENCES}

1. R. Grynberg;BIDPA, 2012, 1, 1-46.

2. M.R. Johnson; C.J. Van Vuuren; W.F. Hegenberger; R. Key; U. Shoko; J. of Afr Earth Sci., 1996, 23, 3-15.

3. R. Graeme; Extr Ind Soc., 2015, 2, 827-839.

4. L. Lu; V. Sahajwalla; C. Kong; D. Harris; Carbon., 2001, 39, 1821-1833.

5. H. Morita; F. Yoshiba; N. Woudstra; K. Hemmes; H. Spliethoff; J. Power Sources., 2004, 138, 31-40.

6. R.M. Flores; Coalification, Gasification, and Gas Storage. In Coal and coalbed gas: fueling the future, $1^{\text {st }}$ Ed.; Elsevier, Oxford, UK, 2014; 167-233.

7. D.A. Bell; B.F. Towler; M. Fan;. The nature of coal. In Coal gasification and its applications, $1^{\text {st }}$ Ed.; William Andrew Publishing, 2010; 1-15.

8. J.A. Mikhlin; Approach to direct liquefaction of high ash low rank coals. In Energy Developments: New Forms, Renewables, Conservation, $1^{\text {st }}$ Ed.; Fred A. Curtis; Pergamon, Regina, Canada,1984; 25-29. 
MMOLOKI MAKOBA, TABOKA MOALOSI, PAUL S. AGACHI, EDISON MUZENDA, TIRIVAVIRI A. MAMVURA

9. S. Toshiyuki; L. Zhihong; T. Makoto; H. Koki;T. Hidehisa; IHI Eng. Rev., 2012, 45, 15-20.

10. F.H. Selvig; W.A. Gibson;Chem. coal Util., 1945, 1, 139.

11. A. Georgakopoulos; A. Iordanidis;V. Kapina; Energy Sources, 2003, 25, 9951005.

12. N. Stojilovic; J. Chem. Educ., 2012, 89, 1331-1332. 